\title{
IMPLICACIONES PARA LA ESTÉTICA DEL PENSAMIENTO DE XAVIER ZUBIRI
}

\author{
VÍCTOR MANUEL TIRADO SAN JUAN \\ Universidad Eclesiástica de San Dámaso (Madrid)
}

\begin{abstract}
RESUMEN: En este ensayo se hace una valoración de la situación actual de la estética y se estudia cuál es la aportación del pensamiento del filósofo español X. Zubiri a la misma. Para ello se reconstruye a grandes rasgos la historia del pensamiento estético hasta el momento actual de modo que sean claramente perceptibles las aportaciones a la estética de la propuesta del pensador español, a la vez que las posibilidades que abre para un desarrollo ulterior de esta disciplina. Para mostrar las aportaciones a la estética de Zubiri se exponen las características fundamentales de su pensamiento en las que destaca su raigambre estrictamente metafísica. Esta raigambre metafísica permite evitar un reduccionismo hermenéutico de la estética tal y como ocurre según el autor en muchas propuestas actuales. Por otro lado, la propuesta zubiriana de incardinar lo estético en una facultad sustantiva como es el sentimiento afectante, permite evitar el intelectualismo y rescatar la autonomía de la dimensión estética de la realidad sin reducirla al bien ni el ser neutro. La propuesta es una alternativa a la teoría de Max Scheler que, no obstante, vuelve a hacerse cargo de la estructura transcendental de la realidad como ocurría en la gran tradición metafísica occidental.
\end{abstract}

PALABRAS CLAVE: historia de la estética; Xavier Zubiri; dimensión estética de la realidad; sentimiento estético; Max Scheler.

\section{Implications for the Aesthetics of Zubiri's Thinking}

ABSTRACT: This essay deals with the assessment of Aesthetics' current situation and the study of the contribution from Spanish philosopher Xavier Zubiri's thought to this discipline. With that aim, the author goes roughly through the history of aesthetic thinking until today, so that the reader may perceive the originality of Zubiri's proposal as well as the possibilities it encompasses for an ulterior development of such discipline. The main features of Zubiri's philosophy - strictly grounded in metaphysics - are described to illustrate his contribution to Aesthetics. This base on metaphysics allows avoiding an hermeneutic reductionism of Aesthetics, as it happens - according to the author - with other current proposals. Furthermore, Zubiri's proposition to refer to the aesthetic as a transcendental faculty -such as the "affecting feeling" - enables escaping from intellectualism and rescuing the autonomy of the aesthetic dimension of reality without reducing it to the good or the neutral being. This proposal is an alternative to Max Scheler's theory that, nevertheless, takes on again the transcendental structure of reality like it happened within Western metaphysical tradition.

KEY WORDS: history of aesthetics; Xavier Zubiri; aesthetics dimension of reality; aesthetic feeling; Max Scheler.

Vivimos un momento particular de la historia de occidente y por lo tanto de la historia de la filosofía. La crisis de la modernidad junto a otros fenómenos inherentes a la particular globalización que inexorablemente se está produciendo nos ha situado en un período de posibles nuevos horizontes y también de perplejidades. Esta condición abierta y ambigua de nuestra época se hace palpable en el hecho mismo de que sólo se la caracterice por relación a la periclitada modernidad: post-modernidad es el apelativo más común que se le da. La época en que vivimos sigue manteniendo algunas actitudes modernas, entre ellas, el recelo frente al pensamiento de pretensiones metafísicas. Esto casa bien con el continuado prestigio de la «ciencia», que sigue acaparando un 
amplio espectro de lo que se considera saber humano. Puesto que se duda de la capacidad de la filosofía para alcanzar conocimientos verdaderos, ésta se sigue considerando ampliamente una mera reflexión crítica pero sin consecuencias ontológicas relevantes.

En el ámbito de la estética esto ha favorecido reflexiones muy atenidas a los procesos artísticos concretos, muy bien situadas en su particular marco social; pero con la contrapartida de una deficiente fundamentación antropología y ontología, la cual, al menos en parte, se considera imposible. Quizá la última propuesta más elaborada en este sentido haya sido la de Heidegger y sus sucesores (en un sentido amplio), dando lugar a una teoría de lo estético de carácter hermenéutico al considerar lo estético esencialmente vinculado a la generación de «sentido" por parte del Dasein y de la comunidad de Daseins a partir del Mit-sein. Es verdad que este enfoque es muy rico, pues da razón de un aspecto fundamental de la vida estética: el «sentido» de lo estético, particularmente de la obra de arte. Sin embargo, este planteamiento no da la importancia debida, me parece, al momento sentiente, aisthitético, de la dimensión «estética» de la realidad y de la vida del hombre.

En otra dirección, el enfoque analítico - fundamentalmente anglosajónque los filósofos que se inscriben en el giro lingüístico dan a la estética, sumerge a ésta, como decíamos más arriba, en un plano meramente crítico, que se ejerce en torno al significado de las palabras y en general al uso del lenguaje. Esta perspectiva tiene, desde luego, sus presupuestos «metafísicos» que, en tanto que presupuestos, dejan de lado la cuestión de la realidad, o, en todo caso, la supeditan a cuestiones de acceso: de lenguaje. El orillamiento de la cuestión de la realidad o su trasposición a cuestiones de lenguaje conlleva el consiguiente orillamiento y supeditación a cuestiones de lenguaje de la dimensión estética de la realidad y de cómo ella «afecta» al hombre ${ }^{1}$. Creo que es en este contexto en el que el pensamiento del filósofo español X. Zubiri cobra importancia para su aplicación a la estética, pues es un pensamiento que, arrastrando en sí la actitud crítica de la filosofía contemporánea, no renuncia a la metafísica (en el sentido de filosofía primera de lo real y la realidad ${ }^{2}$ ), lo cual, a su vez, le permite no sólo evitar el tan frecuente desconocimiento del «pensamiento clásico», sino pensar en y desde la realidad.

La estética es un «momento» de la Filosofía primera, aquel que se propone investigar en «actitud filosófica», esto es, con completa radicalidad, todo lo

\footnotetext{
1 El propio Danto lo da a entender cuando en cierto modo lamenta los límites de su primer enfoque sobre la estética en el marco de la filosofía lingüística y señala la importancia de Hegel en el curso posterior de su obra $C f$. la primera parte de: DANTo, A., El abuso de la belleza, Paidos, Barcelona 2011.

2 No hay una primacía de la cuestión del acceso a la realidad (teoría del conocimiento, — epistemology) sobre la cuestión de la realidad misma; actitud ésta que ha caracterizado a la modernidad; pero tampoco hay primacía de la filosofía primera de la realidad sobre la del acceso. Ambas (filosofía del conocimiento y filosofía de la realidad) son momentos inseparables de la filosofía primera. C f ZuBIRI, X., Inteligencia sentiente, Madrid 1980 pólogo pp. 9 y ss.
} 
concerniente a la vida estética. Podría decirse, y con gran sentido común, que el objeto de la estética es la belleza y el arte; pero, en mi opinión, es más coherente con la mencionada radicalidad del enfoque filosófico, determinar al comienzo su objeto como la vida estética, porque será justamente la propia reflexión la que deberá ir dilucidando con su trabajo, qué es lo que corresponde a la vida estética y cuál es su verdadero sentido. En todo caso, cuando afirmo que la estética es un momento de la filosofía primera, lo que estoy diciendo es que la concepción de lo estético que se tenga no es independiente de la concepción que se adopte en los otros momentos de la filosofía, me refiero a la ontología, a la antropología y a la filosofía del conocimiento. Y así ocurre, desde luego, en el caso de X. Zubiri. Zubiri no escribió mucho de estética, pero sus aportaciones a la ontología ${ }^{3}$, a la antropología y a la teoría del conocimiento tienen un impacto enorme en la estética y desde luego una enorme potencialidad para ella.

\section{Bosquejo de los grandes paradigmas de la Estética}

Para vislumbrar los horizontes que el pensamiento de Zubiri abre a la estética, resultará práctico bosquejar las posiciones estéticas más destacadas a lo largo de la historia del pensamiento así como las de mayor actualidad hoy. Lo estético no es un ámbito de segundo nivel donde no nos juguemos nada de lo que realmente importa en nuestras vidas. Al contrario, la dimensión estética de la vida humana es una de sus dimensiones fundamentales (junto a la teórica, la moral, la política y la religiosa); por ello ninguno de los grandes pensadores desde el alborear del pensamiento ha dejado de consagrar intensos esfuerzos a este asunto.

El primer gran paradigma estético de occidente es el de los pitagóricos, quienes introducen en la reflexión una serie de planteamientos e hipótesis que perduran hasta hoy. Uno de estos planteamientos que perdura hasta hoy - si bien es cierto que el pensamiento marxista primero y el pensamiento de cuño nihilista nietzscheano después (muy relevante en el actual mundo postmoderno) lo dan por finiquitado- es el que identifica la cuestión estética fundamentalmente con la cuestión de la belleza. La belleza, el pulchrum, sería una dimensión primordial de la realidad y también de la vida humana (del ser humano, en tanto que él mismo es real, y de sus producciones artísticas). Además se introduce una peculiar hipótesis sobre la esencia de la belleza, que aletea siempre en la mente de los filósofos, incluso cuando, como ocurre en gran medida hoy, se da por definitivamente superada. Me refiero a la concepción de la belleza como armonía. En el caso de los pitagóricos, además, entendiendo esta armonía como armonía numérica. Es lo que yo suelo llamar

\footnotetext{
3 A pesar del descrédito de este término — sobre todo a partir de la crítica heideggeriana a la onto-teología - me parece muy útil para nombrar ese «momento» de la filosofía primera orientado a la investigación del polo noemático («objetivo») del aparecer.
} 
el racionalismo matematizante. La dimensión estética de lo real sería la belleza, y ésta consistiría en el orden, en la armonía, que afectaría en mayor o menor medida a los seres, y que, en última instancia, afectaría al universo entero, el cual, por su parte, estaría conformado según un logos matemático, es decir, sería

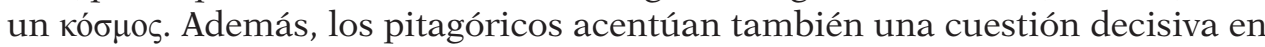
la filosofía en general y en la estética en particular: la cuestión del alma. Habría un alma del mundo, como hay un alma de cada individuo humano. Por esta vía afrontan una de las experiencias más universales de la humanidad (aunque también negada o relativizada por alguno de los paradigmas mencionados de la modernidad y de la postmodernidad): la experiencia de la belleza y el peculiar placer que le va asociado. La experiencia de la belleza se produciría cuando un alma humana «re-conoce» en algún ser la armonía primigenia, que proviene fundamentalmente del alma universal del mundo y que late también en el alma humana en tanto que precisamente alma. Este reconocimiento de la armonía universal (que tendría lugar de una forma automática y espontánea), justamente por su universalidad, sería catártico, curativo para el alma; eh aquí uno de os fundamentos del valor estético.

Platón y Aristóteles recogen esta tradición y la reelaboran cada uno en clave de su propia filosofía. Platón en el marco de su ontología y antropología dualistas; Aristóteles en el marco de su filosofía teleológica hylemórfica con la que pretende superar a su maestro Platón. Ambos son dos hitos fundamentales en la historia de la estética.

El primero, Platón, da carta de naturaleza a una serie de cuestiones que ya ningún pensador puede soslayar. Son las siguientes. Una es la distinción entre «belleza visible» (sensible) y «belleza invisible» (inteligible); la primera pertenecería a este mundo corpóreo que ahora habitamos, y la segunda al mundo inteligible de las Ideas, el cuál sería nuestro verdadero hogar, y al que toda alma humana tiende. Al hacer esta distinción Platón sitúa lo estético en un grado inferior a lo teórico inteligible. Consecuencia de ello ha sido, por un lado, que hasta casi el siglo XX se haya considerado lo estético como un momento inferior de la vida humana y, paralelamente, que se haya considerado a la estética como un momento inferior de la reflexión filosófica. Pero es que a la vez Platón trataba de dar cuenta de la belleza como algo que tenía que ser captado por la inteligencia, puesto que la belleza genuina, la belleza invisible, pertenecería al mundo inteligible de las ideas, con lo que la vida estética de este

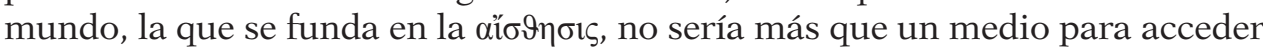
a la intelección de la belleza inteligible, esto es, una «escalera» que solo tiene valor en la medida en que nos permite escalar a lo inteligible, pero que, una vez ya allí, debe ser desechada. En lo que al arte respecta Platón introduce

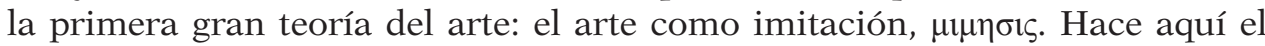
filósofo griego una transposición de la teoría ontológica de la participación a la estética. Así, de manera análoga a como las cosas corpóreas participan de las ideas, a saber, recibiendo su ser y su esencia de ellas por una especie de transmisión ontológica degradativa -una «emanación», que vista de abajo a arriba puede conceptuarse como la relación entre la copia y el original—, de 
esta manera análoga, digo, el artista sería un hacedor de copias. Habría, pues, dos tipos de copias: las cosas reales corpóreas como copias de las Ideas de las que participan (así, por ejemplo, cada uno de nosotros sería una copia de la Idea de Humanidad); y las copias que los artistas humanos hacen de las cosas corpóreas (por ejemplo, la cama que Van Gogh pintó al realizar el cuadro de su cuarto en Arles). La cama real de madera sería una copia de la Idea de cama, y a su vez la cama pintada en el cuadro sería una copia de la anterior cama de madera $^{4}$. Como del original a la copia se produce siempre una degradación, las obras de arte supondrían una manera de ser dos veces degradada. Esta perspectiva, repensada de una u otra forma, se ha prolongado hasta la estética contemporánea, primero repensada y transmitida por todo el platonismo (Plotino, Proclo...) hasta llegar en perspectiva crítica a la estética actual, por ejemplo, en Walter Benjamin ${ }^{5}$, quien mantiene la prioridad del original en el concepto de "aurea» de la obra de arte e indaga las nuevas formas copiativas que el desarrollo de la técnica va posibilitando. Aparece, pues, un «cuarto» tipo de reproductibilidad técnica: las reproducciones impresas (los posters, fotografías...) de las propias obras pictóricas. Las nuevas técnicas electrónicas e informáticas añaden hoy a los análisis de Benjamin una enésima modalidad de copia que ha revolucionado el mundo de la recepción artística.

Aristóteles recoge la teoría del arte como imitación de su maestro en la Poética, pero al construir su teoría de la literatura a través de su estudio sobre la tragedia, introduce una serie de variantes fundamentales. En primer lugar, rescatando la farmacología estética de los pitagóricos, el filósofo macedonio, frente a la visión crítica de Platón, da una visión positiva del arte. La obra de arte, en este caso la tragedia, al imitar acciones humanas terribles, posibilita la кó́ $\alpha \rho \sigma ı \varsigma$ de los lectores. La lectura —dice Aristóteles- «mediante compasión y temor lleva a cabo la purgación de tales afecciones» ${ }^{6}$. Es decir, la dimensión copiativa de la obra de arte, ahora entendida como irrealidad ${ }^{7}$, ya no es un factor negativo, sino, al contrario, positivo. Lo «irreal» se convierte en una fuente, no sólo de conocimiento, sino también de salud para el alma. Justamente porque el drama es irreal alecciona a los contempladores y los protege en su vida real de pasiones destructivas produciendo en ellos afecciones inducidas de los acontecimientos horrendos narrados, es decir, de similares afecciones reales ${ }^{8}$. Aristóteles había situado así la creación estética, aunque fuere de manera inconsciente por parte del artista, en un contexto práctico positivo -i.e., no meramente contemplativo. Las creaciones artísticas, al menos algunas de ellas, reproducirían irrealmente estructuras universales paradigmáticas de la vida humana, con lo que constituirían una fuente privilegiada de sabiduría para el público.

\footnotetext{
4 Platón, República X 596 a y ss.

5 Benjamin, W., La obra de arte en la era de la reproductibilidad técnica; en: Discursos Interrumpidos I, Taurus, Buenos Aires, 1989.

6 Aristóteles, Poética 1449 b 27

7 Aristóteles, Poética 1451 a-1451 b.

8 ARISTóteles, Retórica B 8; 1386a5-1386b7
} 
El pensamiento cristiano recibe en primer lugar la tradición platónica a través del neoplatonismo con pensadores como San Agustín, Dionisio areopagita, San Bernardo, los Victorinos, etc. y después, a través de la escolástica, se va incorporando la tradición aristotélica: Pedro Damián, Guillermo de Auvergne, Roberto Grosseteste; Alejandro de Hales; Juan de la Rochela; San Buenaventura; San Alberto Magno y Santo Tomás, entre otros. Las dos tradiciones funden el pensamiento filosófico con la revelación: «todas las cosas han sido creadas - dice el Libro de la Sabiduría- en número, medida y peso». La doctrina de la armonía, se ve ahora ratificada por la Revelación; y a partir de ella los pensadores cristianos intentan comprender de qué trata ello, qué relación guarda la belleza con el bien, con la verdad y con el alma humana. Se plantea la tesis de la belleza como transcendental y se trata de dilucidar su relación con la verdad y el bien ${ }^{9}$.

Sin embargo, la crisis del siglo XIV da paso a una nueva era. No sólo se tambalea la filosofía clásica y se rompe la unidad de la Iglesia, sino que surge un nuevo método de conocimiento, el de la ciencia empírico-matemática moderna, la cual va a ir cercenando progresivamente la actitud filosófica transcendental a la vez que estrechando la mirada teórica del hombre, que va cediendo el lugar de la dimensión contemplativa de la vida a una actitud de poderío técnico sobre la naturaleza y de disfrute en sus resultados. En este contexto la vida estética auténtica tiene que vérselas con la descarnada lucha por la vida en los conflictivos contextos sociales que tienen lugar en el marco de la revolución industrial (en una humanidad que, con su adscripción cientificista a la nueva ciencia - como denunciara tan lúcidamente Husserl en la primera mitad del pasado siglo-, había perdido el engarce con la gran tradición de la sabiduría filosófica occidental). A la vez, un aparentemente irrefrenable proceso de secularización va generando dialécticamente filosofías ateas y nihilistas en las que lo estético, o bien es concebido en el ámbito del placer empírico (pues ya se ha perdido la dimensión transcendental de la realidad y de la subjetividad) —es el caso de los estetas escoceses del sentimiento-, o bien se interpreta de nuevo como algo subalterno y derivado en el marco de cada propuesta teórica particular, ya se trate de una filosofía materialista, ya de una filosofía abiertamente nihilista o simplemente pragmática. Así, para la tradición marxista, lo estético será un elemento más de la superstructura ideológica, que sirve como arma de legitimación del poder. Lo estético será entonces objeto de crítica cuando se da en el contexto de la burguesía opresora (y aquí entraría también el arte religioso, pues la religión es concebida como un mero instrumento legitimador de la eventual situación social establecida), pero se alentará y promocionará, en cambio, como actividad del artista orgánico al servicio de la revolución, como art engagé. Ni la verdad, ni el bien, ni la belleza son ya categorías privilegiadas, más bien al contrario, quedan sometidas a la

9 Eco, U., Arte y belleza en la estética medieval, Barcelona 2012. De Bruyne, Ed., Estudios de estética medieval, 3 vol., Madrid 1958. 
sospecha y, por lo tanto, desvalorizadas. La categoría que todo lo preside es el poder: la voluntad de poder, la lucha por el poder, el poder sobre la naturaleza... o el poder de la libertad sin el catalizador del bien. El poder es la categoría principal del pensamiento moderno. Esto nos tiene que dar que pensar.

El fracaso del marxismo, como la gran ideología que se postulaba a sí misma para encarnarse revolucionaria y definitivamente en la humanidad, ha dejado las puertas abiertas a dos corrientes filosóficas que son dominantes en nuestros días, naturalmente con múltiples variantes. Una es la gran tradición pragmática y de sesgo empirista anglosajona, matizada por las aportaciones de algún pensador continental, pero «anglosajonizado». Estoy pensando naturalmente en Wittgenstein, pero también en Popper, en Habermas y en otros filósofos que la guerra empujó (física y/o espiritualmente) hacia el Reino Unido o Estados Unidos. De aquí ha surgido un complejo movimiento filosófico, que en gran medida hace una reflexión estética al hilo del «giro lingüístico» y de la tradición empirista y pragmática británica. El giro lingüístico supone también un rechazo de las categorías principales de la metafísica clásica: de la categoría de sustancia, de esencia, de sujeto transcendental o alma y de un logos transcendental interior, todo ello en favor de categorías antagónicas del tipo de: «significado como uso», "parecido de familia», «sujeto empírico», «lenguaje natural social y socialmente construido», etc.; y todo ello en función de intereses pragmáticos de la vida. Así, la estética analítica anglosajona hace una especie de descripción de cómo acontece lo estético en el mundo de la vida y subraya o destaca tres ámbitos de lo estético: 1.- Cierto tipo de prácticas, actividades u objetos (crear arte, apreciarlo; obras de arte...); 2.- Cierto tipo de propiedades, características o aspectos de cosas (belleza, gracia, dinamismo...); y 3.- Cierto tipo de actitud, de percepción, o experiencia ${ }^{10}$. Respecto del arte, siguiendo la crítica de Wittgenstein al esencialismo, niega que exista una esencia del arte; se trataría más bien de contextos sociales en los que se dan ciertos usos del lenguaje y del comportamiento asociados a lo estético. Es una investigación en gran medida del uso empírico del lenguaje, pues de alguna manera niega la posibilidad del acceso fenomenológico individual a la conciencia o le resta importancia, ya que ésta estaría constituida desde fuera por la sociedad en la trama de sus necesidades pragmáticas. Este es un factor común a muchos de los paradigmas filosóficos contemporáneos. La perspectiva es, pues, en gran medida sociológica, una especie de filosofía sociológica y lingüística.

Otra tradición, que guarda cierta relación con la anterior, es la hermenéutica. Podríamos denominarla así. Arranca de Schleiermacher y Dilthey y se refunda con mayor radicalidad y fundamentación filosófica en Heidegger. Puesto que para esta tradición todo es sentido constituido por la subjetividad humana en su existencia fáctica intersubjetiva, entiende lo estético como una de las formas esenciales de la existencia del Dasein en su intrínseco constituir sentido. El

10 Levinson, J., Philosophical Aesthetics: An overview; in: The Oxford Handbook of Aesthetics, Ed. By Jerrold Levinson; Oxford University Press 2003, p. 4 y ss. 
Dasein es el ex-sistente, el ser-ahí, que mundaniza y da sentido a los entes en tanto que Sorge (cuidado). Este «interés» ontológico y primigenio del Dasein como fuente de sentido es el que vincula esta corriente con el pragmatismo anterior. El arte será, entonces, como una segunda dimensión del existir que pone en verdad el existir mismo. Arte y filosofía (poetizar y pensar) acaparan lo esencial de la vida humana: desvelar, hacer manifiesto, el sentido del ser. La belleza es el acontecer de la verdad en la obra de arte, i.e., la re-presentación del sentido primigenio inherente a la vida misma del Dasein. Se podría decir que en el arte el Dasein se expone a sí mismo (se expresa), y al exponerse permite que acontezca su verdad, la única verdad intramundana, pues el Dasein es quien desoculta a los entes, y, por lo tanto, el ser de los entes. En «Las botas» de Van Gogh acontece todo el mundo de la vida de la campesina a la que supuestamente pertenecían ${ }^{11}$.

11 Heidegger, M., Der Ursprung des Kunstwerkes; en: Holzwege, Vittorio Klostermann, 1963: (22-23) «Elegimos... un conocido cuadro de Van Gogh, quien ha pintado más veces tales zapatos. Pero, ¿qué cabe ver ahí? Todo el mundo sabe de qué está hecho un zapato. Si no son zuecos de madera, se componen de suela de cuero y el cuero superior, ambos unidos por costura y clavos. Tal utensilio sirve para vestir los pies. Según su finalidad, el trabajo en el campo o el baile, son su material y su forma diferentes [en definitiva...] El carácter de útil (das Zeugsein) del utensilio reside en su utilidad. Pero, ¿qué ocurre con esta misma utilidad? ¿captamos ya con ella el carácter de utensilio del utensilio? ¿No precisamos, para que esta captación tenga lugar, investigar al instrumento en la realización de su finalidad? La campesina en el campo lleva puestos los zapatos. Sólo aquí son verdaderamente lo que son. Y lo son tanto más auténticamente cuanto menos piense la campesina durante su trabajo en ellos, o los mire o los sienta. Simplemente está y anda en ellos. Es así como cumplen los zapatos verdaderamente su función. Ciertamente en este proceso del uso del utensilio debe dársenos la instrumentalidad del instrumento. Por el contrario, mientras nos representemos genéricamente un par de zapatos o simplemente los zapatos vacíos inutilizados, jamás experimentaremos lo que es la esencia del utensilio en tanto que tal. No podremos jamás constatar por el cuadro de Van Gogh donde están estos zapatos. Alrededor de ellos no hay nada que nos indique para qué puede servir, sólo un espacio indeterminado... De la oscura cavidad del interior desgastado de los zapatos nos miran fijamente los esfuerzos del duro caminar en el trabajo. En su rígida pesantez está contenida la tenacidad del lento caminar por los divididos surcos siempre iguales de los sembrados por los que corre un áspero viento. Sobre el cuero reposa la humedad y la riqueza del suelo. Bajo las suelas se agita la soledad del camino campestre por la oscura noche [...] Este utensilio pertenece a la tierra y encuentra su acogimiento (su hogar, su refugio) en el mundo de los campesinos. A partir de esta pertenencia hogareña adquiere el utensilio mismo su autosubsistencia. Pero todo esto lo vemos quizá sólo en los zapatos del cuadro. La campesina, por el contrario, simplemente lleva los zapatos [...] El carácter utilitario del utensilio reside únicamente en su utilidad. Y esta misma reposa en la plenitud de un ser esencial del utensilio. Lo denominamos el abandono (Verläßlichkeit). Gracias a él ha podido la campesina penetrar por el utensilio en la llamada silenciosa de la tierra, gracias al abandono del utensilio está cierto de su mundo. Tierra y mundo están sólo ahí, en el utensilio, para ella y para aquellos que son como ella [...] decimos «sólo» y erramos, pues el abandono del utensilio da primeramente al mundo su ocultamiento y asegura a la tierra la seguridad de su constante afluencia» 


\section{ZubiRI EN EL CONTEXTO DE LA HISTORIA DE LA ESTÉTICA}

¿Cómo se sitúa en este contexto Zubiri y qué peculiar estética cabe elaborar a partir de su pensamiento?

Lo más característico del pensamiento de Zubiri es, quizás, que a pesar de construirse a partir de la fenomenología y hacerse a su vez cargo del peculiar giro postmoderno que tiene lugar tras de Heidegger, pretende, no obstante, ser una filosofía estrictamente "metafísica». Es, ciertamente, una filosofía estrictamente metafísica, porque se articula toda ella en torno a la realidad. Claro que reconoce el «carácter destacado» del hombre, única sustantividad abierta intramundana, pero su filosofía no se queda en una antropología, aunque fuere transcendental. Esto le permite dialogar, no sólo con los pensadores contemporáneos (salvo los del giro lingüístico, por los que nunca se interesó ${ }^{12}$ ), sino con la filosofía clásica: la filosofía escolástica del ser y la filosofía griega.

Su metafísica no es una metafísica del ser. Es sabido que considera un deslizamiento general de la filosofía occidental lo que él llama la «entificación de la realidad», deslizamiento correlativo a la «logificación de la inteligencia», el cual sería consecuencia de un cierto error «idealista» propio de gran parte del pensamiento occidental. Justamente «idealismo» sería anteponer las «ideas» humanas a la realidad. Esta anteposición tendría que ver, sin duda, con la primacía dada por Platón a las Ideas, pero también, cuando desaparece la supremacía ontológica de dichas Ideas en favor del antropocentrismo moderno, se antepondrían las ideas creadas por el hombre a la realidad. En el caso de Zubiri y en lo que al platonismo respecta, no es sólo que las Ideas no existan separadas (que no sean realidades de "otro mundo», y además superiores a las de éste), sino que tampoco serían canónicas respecto de la realidad. Por el contrario, las ideas serían construcciones de la inteligencia humana (del dinamismo del logos humano) a partir de la impresión sentiente de realidad ${ }^{13}$, con lo que es la realidad sentida la que es realmente canónica y guía la tarea racional humana en búsqueda de su esencia. La realidad está esenciada, pero como es trans-cendental excede todo contenido, desborda cualquier esencia concreta hacia un más siempre abierto. De este modo, no sólo todo lo real es abierto, sino que todo canon (incluido todo canon estético) será también necesariamente abierto. Respecto el idealismo antropocéntrico moderno, justamente la condición metafísica inherente a la adscripción zubiriana a la prioridad en todos los órdenes de la realidad o descarta ab initio, pues la

12 Probablemente no sólo por el sesgo ametafísico de este enfoque filosófico, sino también por considerarlo una modalidad de «logificación de la inteligencia» (anteponer la intelección dual del logos a la intelección impresiva y sentiente de lo real). Al desprecio que Russel mostró sobre la obra de Zubiri corresponde el aparentemente completo desinterés de éste por aquél.

13 Ciertamente este enfoque tiene que ver con la influencia de Occam en el pensador español. En esta dirección sí que cabe una cierta afinidad con la tradición británica, pero otros muchos rasgos de su pensamiento en cambio lo apartan de ella. 
inteligencia humana (y la realidad humana en general) se sustenta en y se dinamiza a partir de la realidad, que siempre la precede en todos los órdenes y a la que esta originariamente re-ligada.

Por consiguiente, tenemos varias características fundamentales que especifican el pensamiento filosófico de Zubiri y que determinan un peculiar «enrutamiento» para una estética filosófica. Su condición estrictamente metafísica determina una precisa orientación del pensar y de los problemas fundamentales, que se sitúan siempre en un orden transcendental, justo una perspectiva que gran parte del pensamiento actual ha perdido. Se ha perdido, en gran medida, bien por una falta de radicalidad teorética o bien por haber tomado, como decía antes, una dirección antropocentrista, reduciendo el enigma al hombre, es decir, por un antropocentrismo exagerado. Esto es palpable tanto en el paradigma hermenéutico, que sitúa en el hombre el origen de todo sentido, como en el paradigma del giro lingüístico, que, análogamente a Kant, cercena la capacidad humana para acceder al misterio, reduciéndolo todo según los límites de nuestro lenguaje (en aquél, según los límites de la «razón»). La falta de radicalidad teorética ha situado el saber a un nivel de filosofía segunda, abandonando los problemas fundamentales de la filosofía primera y en particular perdiendo, como digo, la dimensión transcendental de lo real, incluida la dimensión transcendental del hombre.

No obstante, que Zubiri esté abierto a la metafísica, cuando la mayoría de los paradigmas filosóficos actuales se consideran a sí mismos post-metafísicos, no significa que abandone la antropología como filosofía primera, pues, efectivamente, el hombre es la única realidad intramundana capaz de la verdad, de la belleza y del bien; es decir, el único que accede a lo real en tanto que real gracias a su condición espiritual, i.e., el hombre es la única sustantividad inteligente y abierta (mientras no aparezca otra). De hecho, realidad es para Zubiri en primera instancia «formalidad de realidad», lo que quiere decir, modo de quedar las cosas ante la inteligencia sentiente como siendo «de suyo» lo que son. Esto no significa que realidad sea un «sentido» constituido por la subjetividad humana. Todo lo contrario, quiere decir que sólo la subjetividad humana es capaz de acceder a lo real qua real; los animales superiores, que son la forma de sustantividad más elevada por debajo del hombre, acceden a la conciencia, pero su conciencia es meramente estimúlica, no consiguen acceder a lo transcendental y, por lo tanto, no son espíritus, no son personas.

No obstante, la personeidad humana no es meramente intelectual. Ni somos puras inteligencias - pues nuestra inteligencia es sentiente (no somos puros espíritus, sino espíritus encarnados), ni somos sólo inteligentes. La filosofía clásica había subrayado ¡no cabe duda! nuestra condición inteligente, y a

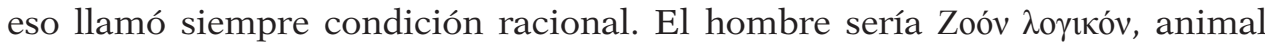
racional. A eso añade - desde luego lo hacen inequívocamente los filósofos cristianos- la voluntad. La voluntad clásica no es la voluntad moderna, que queda reducida a libre arbitrio, a pura (sólo) libertad como capacidad neutra de autodeterminación, sino que, por el contrario, es capacidad de determinarse, ¡sí!, pero no abstractamente, sino siempre en un contexto de posibilidades 
reales y, además, determinadas axiológicamente según la polaridad hacia el bien. Sin embargo, en el pensamiento clásico no hay «afectividad»; o mejor dicho, la afectividad queda relegada a y subsumida en la voluntad, dependiendo de que alcancemos verdaderamente el bien al que la voluntad por naturaleza tiende (surgirán entonces las pasiones positivas) o de que éste se nos resista (caso en el que surgirán las pasiones negativas). Zubiri, como otros pensadores contemporáneos, postula, por el contrario una tríada de facultades espirituales sustantivas, en el caso del filósofo vasco: inteligencia sentiente, voluntad tendente y sentimiento afectante. La esencia humana en su «función transcendental» ha determinado una sustantividad espiritual o sustantividad abierta: abierta a la verdad de lo real, a la bondad de lo real y a la belleza de lo real. También esto va a ser decisivo para la estética, como vamos a ver.

\section{Estética en CLAVE ZUBiriana}

¿Cuáles serían, pues, las características de una estética construida sobre la base del pensamiento de X. Zubiri?

\subsection{Una estética metafísica y del sentimiento}

La condición estrictamente metafísica del pensamiento de Zubiri sitúa a una estética que se construya en su inspiración en una perspectiva también metafísica. ¿Qué significa esto? Significa fundamentalmente dos cosas. La primera es que se trata de una estética estrictamente filosófica, esto es, una estética como momento de la filosofía primera, que no se confunde con ningún enfoque particularista de lo estético, ya sea la psicología del arte o la sociología del arte o la neuroestética, etc. Es decir, parte de una reflexión sobre lo estético que pretende ser radical, sin presupuestos injustificados; ha de ser, pues, una estética fenomenológica. Evidentemente, considero que «enfoque fenomenológico» $\mathrm{y}$ «enfoque metafísico», no sólo no se contraponen y excluyen entre sí, sino que, todo lo contrario, son inseparables; lo que ocurre es que hay una dirección noológica y otra metafísica de dicho enfoque fenomenológico.

Cuando hablamos, pues, de una "estética metafísica» nos referimos a una estética que describe el polo noemático de la vida estética, que surge en la conciencia en la aprehensión impresiva, o sea, que se orienta a esclarecer la dimensión estética de lo real. En este respecto Zubiri se inserta en toda la

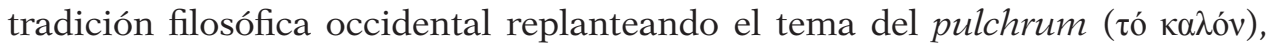
pero también la cuestión del estatuto ontológico de la obra de arte. Esto contrasta con la debilitación de la cuestión de la belleza en la estética actual.

En realidad, hay al menos dos épocas en el desarrollo intelectual de Zubiri a este respecto. Una llegaría hasta la publicación de Sobre la Esencia, pues hasta ese momento (en cierto modo reviviendo las dudas escolásticas sobre si el pulchrum es o no un transcendental propio o va más bien subordinado al bien 
—la belleza como «resplandor de la bondad»—) no considera el pulchrum un transcendental. Los transcendentales conjuntos serían únicamente el bonum y el verum ${ }^{14}$. Pero en una segunda etapa, al menos a partir de 1975, fecha del curso "Reflexiones filosóficas sobre lo estético», Zubiri ya considera la belleza, el pulchrum, una dimensión transcendental de la realidad.

El debate, que, como digo, ya había tenido lugar con no poca profundidad entre los medievales, consistía en indagar qué es lo que la belleza y el bien añaden a las notas «objetivas» de las cosas. Las notas «objetivas» de las cosas son constatadas por la inteligencia, y esa «constatación» - mejor diríamos con Zubiri, esa aprehensión de lo real qua real- sería, justamente, la verdad. ¿Qué añaden, entonces, el bien y la belleza a las propiedades «objetivas» de la cosa aprehendidas por la inteligencia? La solución clásica consiste en postular que la cosa es buena en tanto en cuanto es apetecida por la voluntad, es decir, lo real, que es lo que es tal y como revela la inteligencia, «adquiriría» como una "propiedad» de segundo orden al entrar en relación con la voluntad de un espíritu. Efectivamente, buenas son para nosotros los seres humanos aquellas cosas que nos «satisfacen», y toda satisfacción surge del cumplimiento de una tendencia. La naturaleza humana tendría unas tendencias innatas que le pertenecen por esencia, lo cual determinaría unos bienes universales, o, si se quiere, los bienes propios de la ley natural. En una primera instancia, el ser qua ser sería el bien primordial: el bonum como propiedad transcendental del ente en relación a las tendencias de los seres animados y de nosotros, seres racionales. De aquí que todo ente tenga una tendencia a «seguir siendo», a no desaparecer en la nada. Este planteamiento se reproduce de manera análoga en la filosofía zubiriana de la realidad, pero en un modo que experimenta cambios fundamentales debido al rechazo que Zubiri hace de la primacía del ser y del sistema categorial, en favor de la primacía de la realidad y de la introducción de la nueva perspectiva metafísica de la dimensionalidad de lo real que se añade al concepto de categoría ${ }^{15}$.

Santo Tomás hizo una serie de consideraciones en torno a esta cuestión, que perfilaron de una manera muy interesante - genial, diría yo, incluso- las también extraordinarias especulaciones previas de su maestro San Alberto Magno sobre el tema; magníficas, ciertamente también, pero dubitativas y zigzaguean-

14 Zubiri, X., Sobre la Esencia, 432 «En definitiva, el orden transcendental es el orden de las cosas reales en cuanto reales, esto es, como algo "de suyo». Estas cosas son "de suyo» en y por sí mismas; son los transcendentales simples (res y unum). Y son también "de suyo» respectivas; son los transcendentales complejos, bien disyuntos (mundo), bien conjuntos (aliquid, verum, bonum), de los cuales éstos se fundan en los disyuntos (...) esta estructura reposa, pues, sobre dos transcendentales primeros: realidad y mundo; transcendental simple aquel, transcendental complejo éste»

15 Este es un asunto decisivo, pero de enorme complejidad metafísica, en el que no puedo entrar aquí. En todo caso en base a él puede hablarse con propiedad del pulchrum no sólo como transcendental, sino también de la dimensión estética de lo real. Es una cuestión que desarrollaré en próximas publicaciones y que trato ya en; Tirado, V., «Esencia y dimensionalidad de lo estético», en: Lo Estético (ed. Alejandro Trapero), Universidad Eclesiástica San Dámaso, col. Presencia y Diálogo (en prensa). 
tes sobre esta dificilísima cuestión. Zigzagueantes entre una concepción ontológica de la belleza según la cual ésta sería el «resplandor de la forma en cada una de sus notas», y una concepción relacional según la cual la belleza surgiría de la «relación de la cosa con el espíritu que la aprehende» ${ }^{16}$, sería como el correlato noemático de una vivencia fronteriza entre la pura «aprehensión neutra» de la cosa y el surgimiento del deseo, es decir, que la belleza sería como un correlato intencional que aparecería al espíritu humano entre el ser de la cosa que aparece a la inteligencia a través de los sentidos y el ser de esta misma cosa en tanto que deseada por la voluntad (i.e., en tanto que «buena»). Sin embargo, como decía, Santo Tomás en la Suma Teológica perfila la cuestión de una manera genial, enfoque que va recoger Kant en la Crítica del Juicio. Efectivamente, en la Suma Teológica leemos ${ }^{17}$ :

«La Belleza y el Bien son la misma cosa en el sujeto al que cualifican (in subiecto), porque se fundan sobre la misma realidad (super eadem rem), esto es, sobre la forma del ser determinado. Y por esto ambos son objeto de alabanza o de aprecio. Sin embargo, difieren por su definición (ratione differunt). Porque el bien se refiere formalmente al apetito de lo real: bien, en efecto, es lo que todos apetecen, y por tanto, se sitúa en el orden de los fines, puesto que el deseo o el apetito son, por decirlo así, como una tensión hacia la realidad. La belleza, por el contrario, se define en función de las facultades de conocimiento: en efecto, se dice bello aquello cuya vista deleita. [Es por esto por lo que] la belleza consiste en la relación conveniente (de la forma a la conciencia), ya que la sensibilidad no disfruta más que las proporciones convenientes de las cosas que son análogas a su propia armonía. Por otra parte, la sensibilidad es cierto ordenamiento (ratio) como toda facultad de conocimiento. Y puesto que el conocer se hace por asimilación de una representación y la representación refleja la forma, la belleza se sitúa en sentido estricto y propio en el orden de la causa formal (y no de la causa final)»

El texto es magnífico. A mi parecer es esta posición de Santo Tomás la que da la pauta a Kant en la Crítica del juicio para concebir el juicio reflexionante estético de belleza en función del placer producido por la armonía de las facultades de sentir y conocer en su libre juego. Bien y belleza, pues, sólo tienen sentido en relación al espíritu (en Kant, al sujeto transcendental); pero mientras que el bien hace relación al orden de los fines, i.e., a la voluntad (al orden de la causalidad final, dice Santo Tomás), la belleza hace relación al orden de las facultades cognoscitivas, i.e., al orden de la forma (de la causalidad formal, dice Santo Tomás). De aquí que Kant, en asombrosa sintonía con Tomás, caracterice el juicio reflexionante estético, es decir, la experiencia de la belleza, como desinteresado, aconceptual, de universalidad subjetiva y que pone en juego una finalidad sin fin (es decir, una pura "formalidad teleológica»), y, que, en base a ello, defina la experiencia de la belleza como ese peculiar placer que experimentamos cuando al contemplar «algo» las facultades de conocimiento

16 San Alberto Magno, Summa de Bono (1246) q. 12.

17 Sто. Toмás, Suma Theologica, I, q. 5, a. 4, ad 1m 
—de manera particular la sensibilidad y la imaginación, pero también el entendimiento- se usan sin ningún fin práctico ni cognoscitivo y entran en una relación de armonía entre sí. Kant, como en tantos otros aspectos de su pensamiento, no hace sino trasladar al sujeto transcendental lo que la filosofía clásica postulaba para las realidades mundanas o para la relación de estás con el espíritu. Ahora la belleza sigue siendo armonía, pero no en la cosa sino en el juego libre de las facultades subjetivas. Y vemos que Santo Tomás se había encargado ya de poner el acento en la subjetividad espiritual.

Esto ha nutrido gran parte de la estética contemporánea. Sólo la teoría de los valores de Max Scheler supuso una alternativa al subjetivismo transcendental kantiano, que, por otra parte, al aislar al sujeto de lo nouménico dejaba el valor estético, como también la verdad real, en una gran indefinición. La universalidad subjetiva propia de la belleza no garantizaba ninguna verdadera legitimidad universal al valor estético que no fuese la mera exigencia «subjetiva» de dicho valor. Frente a esto, Scheler reivindica un nuevo modo del ser o un nuevo tipo de objetos: el ser como valor, el cual compartiría con las Ideas platónicas su validez universal y su peculiar modo de ser aprehendidas por parte del espíritu, mediante una peculiar facultad suya, que el pensamiento clásico había pasado por alto: la estimativa (tal y como el genio lingüístico de Ortega la bautizó). Si la inteligencia aprehende el ser neutro, ya sea sensible o ideal, la estimativa captaría los valores, otro tipo de idealidades.

No son pocos los investigadores que hoy rastrean la genial propuesta de Scheler ${ }^{18}$. Sin embargo, Zubiri propone una teoría alternativa. Coincide con Scheler - y en parte con Heidegger y otros fenomenólogos-, en que junto a la inteligencia y la voluntad hay una tercera facultad del espíritu: el sentimiento. Pero para el filósofo español el sentimiento, como la inteligencia y la voluntad, tiene un carácter sentiente. No puede concebirse entonces como una facultad de «lo universal», que, en el sentido clásico, se contrapondría a la sensibilidad (cuyos objetos serían siempre particulares). El intento zubiriano de pensar de forma no platónica inspira toda su obra. La dicotomía entre particular-universal se disuelve a través de una nueva categoría: lo factual, y paralelamente la dicotomía sentir-inteligir también se disuelve en la unidad dual de la intelección sentiente. Por otra parte, la dicotomía inteligencia-voluntad se estructura ahora en una unidad tríadica entre inteligencia, sentimiento y voluntad.

El sentimiento se nutre de lo real mundanal que nos afecta a través de los sentidos (de la inteligencia sentiente); sin embargo, no se trata de que mis estados subjetivos queden constituidos como efecto de la actuación de las cosas del mundo sobre mí. Esta fue la forma como lo concibieron los filósofos escoceses del sentimiento y que, en cierto modo perdura en Husserl, cuando éste concibe

18 Entre nosotros Pilar Fernández BeITES (cf. «Affective reason and values: Beyond subjectivism and objectivism», en: Anuario Filosofico 45(1):33-67 - January 2012: «El deber y lo «justo» en la ética fenomenológica: hacia una ética deontológica material» en: Anales del Seminario de Historia de la Filosofia 34 (3) · October 2017) y Leonardo Rodríguez Dupla (cf. La primacía del amor: estudios sobre la ética y la antropología de Max Scheler, Avarigani, Madrid 2019). 
los actos intencionales valorativos como actos fundados sobre actos objetivantes previos. La tesis de Zubiri consiste más bien en que el sentimiento, al igual que la inteligencia, actualiza una dimensión de lo real para la que la inteligencia y la voluntad serían «ciegas»: justamente se trataría de la dimensión estética de lo real. Esta dimensión tiene una vertiente transcendental: el pulchrum, como dimensión transcendental de lo real, y una vertiente talitativa: las bellezas concretas, la belleza de las cosas reales concretas en tanto que naturales o incluso en tanto que útiles, pero también y de forma particular, de las obras de arte. El sentimiento, decimos, no es concebido (como sí lo hacen, empero, el empirismo y el racionalismo modernos - pero también la mayoría de las filosofías contemporáneas-) como el «estado subjetivo mío» provocado por lo real, pero ya mío como sustancia aislada y, consiguientemente, «separada de» esto real. Justamente al contrario, el sentimiento sería un atemperamiento a lo real, un estar respectivo. Del mismo modo que en la intelección lo real aprehendido forma "parte inseparable» del acto de aprehensión —es realidad aquende la aprehensión, aun comunicando con el allende al que respectivamente remite; es un "momento» de una única actualidad ${ }^{19}$ - ahora lo real "afectivamente sentido» forma «parte» del sentimiento mismo. No es que al visitar el museo de Orsay en París y contemplar el "Jardín del artista en Giverny» de Monet, se produzca en mi interior un sentimiento como vivencia aislada, y ahora ya dejo de mirar al cuadro y miro hacia mi sentimiento interior, de modo que el cuadro sería como un interruptor de dicho extraño sentimiento (causa externa), pero que queda al margen de él. Al contrario, el sentimiento se nutre de las cualidades estéticas del cuadro mismo, es inseparable de ellas. Es el cuadro el que es hermoso, por su suavidad y al mismo tiempo íntimo y acogedor, excitante... Ya Platón censuraba en su República la armonía lidia mixta por lastimosa, y la jónica y lidia por ser armonías muelles en caracteres indolentes (sólo válidas para el desenfreno), en cambio, incitaba a promocionar la armonía dórica y frigia, la primera por su carácter «fuerte», y la segunda por su carácter «calmo y afable» ${ }^{20}$.

Efectivamente, la formalidad de realidad y el contenido ${ }^{21}$ se interpenetran (dringen sich durch... término ya utilizado por Husserl para referirse a la

19 Este es un aspecto complejísimo y nuclear del realismo transcendental zubiriano, que abre un nuevo horizonte frente al idealismo transcendental de Husserl o las nuevas formas de «dealismo» hermenéutico asentadas en el pensamiento de Heidegger. El todo respectivo que tiene lugar entre lo real aprehendido y la aprehensión misma es un todo de actualidad, no lo es ni de intencionalidad - pues esto sería un acto exclusivamente espiritual subjetivoy menos aún de causalidad como postula el naturalismo. Pues bien, se trata de que hay también un actualidad sentimental, no sólo intelectiva. Cf. mis dos obras Intencionalidad, actualidad y esencia. Husserl y Zubiri, ed. Universidad Pontificia de Salamanca, Salamanca 2002 y Husserl et Zubiri. Six études pour une controverse, l'Harmatan, Paris 2005.

20 Platón, República, 399 a.

21 La actualidad de lo real en la inteligencia, según la descripción fenomenológica que Zubiri hace, consta en el momento de alteridad a su vez de dos momentos inseparables: la formalidad o modo de quedar el contenido, y el contenido mismo donado a través de los diversos sentidos. 
interpenetración de «momentos» diversos en la vivencia intencional) de una peculiar manera, y esta interpenetración actualiza lo estético de cada una de ellas: lo estético de la pura realidad (formalidad) y lo estético de los contenidos (la «forma», en la filosofía clásica). Pues bien, es el sentimiento el que actualiza, i.e., el que «desvela» estas cualidades estéticas. Este desvelarse no es ni teorético ni práctico, es sentimental, actualiza un «ambiente» real que envuelve al espíritu en su estar sentiente en lo real. Lo que la propuesta de Zubiri empuja a pensar es: por un lado, la congenereidad entre lo real y el espíritu: el espíritu acoge la actualidad de lo real qua real en la inteligencia, qua bondad en la voluntad y qua belleza en el sentimiento; y, por otro lado, la propuesta zubiriana inclina a pensar también la extraña unidad del espíritu en su diversidad de facultades, a la vez que en su fusión con el cuerpo ${ }^{22}$. Se ha defendido a menudo que también se daría en el filósofo español una preeminencia de lo teórico (por ejemplo, Antonio Pintor Ramos ha hablado del «inteleccionismo» del pensamiento de Zubiri: no sería «intelectualismo», pero sí inteleccionismo ${ }^{23}$ ); sin embargo, creo que no es así, en realidad Zubiri se acerca mucho a la concepción agustiniana de la unidad del espíritu, según la cual amar y conocer son inseparables ${ }^{24}$. Inteligir, querer y sentir temperantemente se dan fundidos entre sí.

Este enfoque de Zubiri, que entiende la vida estética como la vida en el «ambiente» sentimental en la respectividad con la dimensión estética de lo real, se me antoja enormemente sugerente y fructífero. Se trata de una dimensión que atraviesa la vida entera del hombre y que alcanza particular dominancia en la vida del artista. El artista vive en un ambiente estético fulgurante que envuelve toda su vida personal y que es una fuente inagotable de inspiración. Este ambiente se genera desde la dimensión estética de la realidad misma en su doble respecto transcendental y talitativo, a la vez que tiene, junto a este respecto de la realidad mundanal, una vertiente "subjetiva», pues la formalidad es a una de la realidad qua realidad y del espíritu en tanto que modo de quedar aquella en él. Por una y otra vertiente el artista "constituye» verdaderamente un «mundo» particular de belleza que lo envuelve todo y que contagia al público e incluso a la sociedad entera.

22 La inversa articulación de las cosas reales en propiedades y dimensiones (como «acusación» ad intra de su unidad esencial desde la pluralidad de sus notas — propiedadese inversamente como plasmación de esta unidad esencial ad extra en la pluralidad de sus notas - dimensiones- Cf. ZuBIRI, X, Sobre la realidad, Alianza Ed.\&Fundación Zubiri, Madrid 2001, pp. 124-126; ZuBIRI, X., Sobre la esencia, pp. 126-134 y 491-498) vale también para la realidad humana, en tanto que espíritu y en tanto que espíritu encarnado.

23 Pintor Ramos, A., "Intelectualismo e inteleccionismo», en: A.A.V.V., Del sentido a la realidad. Estudios sobre la filosofía de Zubiri, Editorial Trotta / Fundación Xavier Zubiri, Madrid, 1995, pp. 109-128.

24 San Agustín, De Trinitate, L IX, cap. 3. 


\section{2. ¿Una estética postmoderna?}

¿Qué es la belleza transcendental? ¿En qué sentido cabe decir que lo real, por el mero hecho de serlo, al margen de su contenido, de su «forma», es bello, es decir, produce en el espíritu un temple de ánimo estético positivo? Correlativamente, la «belleza talitativa» será la belleza de las cosas por su contenido (por su «forma» en sentido clásico). Las vanguardias artísticas pareciera que discurren por el camino de la renuncia a todo ideal de belleza. La ineludible estrechez de los cánones —en el horizonte de una realidad de suyo abiertaha conducido a una apertura aparentemente total al respecto, es decir, a que el arte se sitúe en la apertura misma sin ningún canon. Hoy más que nunca se afirma que «sobre gustos no hay nada escrito» y que el valor estético nada tiene que ver con la belleza ${ }^{25}$. De hecho el feísmo es un movimiento vanguardista muy potente. Aquí, como en el tema de la verdad surge una disputa en el seno de la filosofía en general -y también en el seno de los intérpretes de Zubirisobre la posibilidad de una jerarquía de bellezas. En mi opinión la belleza sigue siendo un valor estético fundamental. Los cambios en el canon no significan el relativismo estético en el sentido escéptico de que todo valdría lo mismo o en el sentido de que el único sustento de la apreciación sería la opinión de los expertos por el mero hecho de ostentar ese reconocimiento social ${ }^{26}$. La teoría zubiriana de la esencia de lo real como «unidad clausurada de notas-de que dan suficiencia constitucional a la cosa» apunta un camino de continuidad con la teoría clásica de la belleza como armonía producida por la unidad que articula en respectividad esencial la multiplicidad de notas que la constituyen ${ }^{27}$. Lo que ocurre es que las formas de unidad son infinitas, es un horizonte abierto. Y, sin

25 Pero el asunto no es tan sencillo como pudiera parecer, las observaciones de Danto al respecto so muy aleccionadoras. Por ejemplo, DAnTo, A., El abuso de la belleza, Paidos Barcelona 2011, p. 51: «Aunque la belleza hubiera demostrado ser mucho menos esencial para las artes visuales de lo que la tradición filosófica había imaginado, eso no quería decir que no fuera esencial para la vida humana (...) la necesidad de la belleza en los momentos extremos de la vida está profundamente arraigada en lo humano (... pero) la belleza es solamente una cualidad estética entre un inmenso abanico de cualidades estéticas, y la estética filosófica estaba en un callejón sin salida por haberse concentrado demasiado en la belleza. Sin embargo, la belleza es la única cualidad estética que también es un valor, como la verdad y la bondad. Y no simplemente uno de los valores que nos permiten vivir: es uno de los valores que definen lo que significa una vida plenamente humana».

Sobre esta dialéctica entre la existencia e inexistencia de cánones estéticos en la polémica entre los defensores del arte «clásico» y los de las vanguardias, cf. Kessler, Mathieu, Les antinomies de l'art contemporain, Puf, Paris 1999.

26 Por ejemplo la teoría institucional del valor estético de George Dicki (cf. Art and the Aesthetic: An Institutional Analysis, Cornell University Press, 1974; también: Art and Value, Blackwell, 2001).

27 Paradigmático es el pensamiento de Plotino al respecto. Por ejemplo, Eneada I, 6: (26-27): «una proporción armónica de las partes entre sí y con el todo, con la adición de un colorido agradable ... la belleza de todas las cosas sin excepción consiste en ser simétricas y armónicamente proporcionadas» 
embargo, no todo alcanza el mismo grado de simplicidad en la armonización de sus «partes». No toda obra de arte es capaz de unificar sus «materiales» con el mismo acierto ${ }^{28}$. La investigación de este asombroso aspecto está abierta, tanto más cuanto que la historia del arte pone a nuestra disposición un campo enormemente rico para la estética, él mismo abierto.

Por otra parte, es cierto que, como estamos viendo, que Zubiri recupera - ya lo he apuntado antes - la perspectiva transcendental de la filosofía, y así, la cuestión del pulchrum como transcendental. Esto quiere decir, ciertamente, que lo real qua real sería bello por el mero hecho de ser real. Como la realidad es la inespecífica formalidad que atraviesa todo lo real concreto, esto es, dotado intrínsecamente de "contenido» («forma» o «talidad»), esta condición de belleza transcendental no es fácil de ser pensada. Sí resulta más fácil, como hemos visto, lo que he llamado «belleza talitaliva», pues lo es en función del contenido, y esto sí que se sitúa en la línea de toda la tradición estética, como ya he señalado. La propuesta zubiriana, pues, permite simultáneamente enlazar con la tradición, pero pensando hacia adelante y abriendo nuevas perspectivas; se evita el estatismo anquilosante, y a la vez el modernismo ignorante de la tradición y de los motivos de su propia génesis.

\subsection{Una teoría del arte a partir de la distinción entre «cosa-real» $y$ «cosa-sentido»}

Esta distinción zubiriana entre «cosa-real» y «cosa-sentido», muy controvertida entre los intérpretes, es, no obstante, una clave fundamental para una estética de inspiración zubiriana. ${ }^{29}$ En realidad marca la frontera entre dos paradigmas de filosofía primera: lo que yo llamaría fenomenología clásica que engarza con la metafísica clásica en algún sentido- y la filosofía de cuño hermenéutico. Por «filosofía de cuño hermenéutico» entiendo aquí la posición filosófica que tiende a acentuar la subjetividad humana como donadora de sentido dejando en suspenso la cuestión del sentido intrínseco a la realidad. Desde esta perspectiva tiende a postular la imposibilidad de un acceso del espíritu humano inmediato a la realidad en sí. Se trataría, pues, de la posición filosófica que afirma que la filosofía primera es una teoría primera de la interpretación, una antropología que sacaría a la luz las fuentes subjetivas de todo "sentido»: el «sentido» que el ser humano $d a$ a lo real y a la realidad. Por el contrario, la

28 Escribo «materiales» (entre comas), porque no me refiero aquí únicamente al constitutivo material o "aisthitético» sobre el que «reposa» la obra de arte, sino también al contexto espiritual que determina su modo de aparecer al público. Como vengo afirmando, el valor estético se realiza en la respectividad entre cosas mundanales (naturales o artificiales, como la obra de arte) y la persona humana: tanto el creador como el contemplador

${ }_{29}$ Entre los intérpretes más destacados que tienden a acentuar la importancia de la cosa-sentido frente a la cosa real en el pensamiento de Zubiri, Gracia Guillén, D., El poder de lo real. Leyendo a Zubiri, Fundación Xavier Zubiri, Triacastella Madrid 2017, II, 8: La actividad del logos pp. 315 y ss. También, Barroso, O., «Esencias y hechos en Zubiri. ¿En qué sentido puede entenderse la filosofía de Zubiri como una fenomenología?», Revista de Filosofía, 38 (2013), 29-52. 
«fenomenología clásica» y la «metafísica clásica» consistirían en la posición de filosofía primera que supone que el sujeto es capaz de acceder inmediatamente a lo real y a su «sentido» intrínseco, aunque, ciertamente a partir de ese acceso primigenio (experiencia originaria) vaya tejiendo en torno a ella una cada vez más espesa red de sentido, ahora sí, dado o constituido por ella.

Ciertamente vivimos en un «mundo» constituido por la intersubjetividad transcendental, pero este "mundo» interpretado y construido se apoya sobre un «mundo» originario real previo al que la inteligencia accede como una luz iluminadora, pero que ella no constituye, sino que más bien lo recibe y lo ilumina. Escribo «mundo» entre comas, porque ya él comprende como dos vertientes: por un lado, el mundo objetivo que se da en las impresiones sentientes mediadas por nuestro cuerpo, y, por otro lado, el mundo como apertura de la formalidad de realidad actualizada por la propia realidad espiritual, la cual está ella misma en el mundo en el primer sentido a través de su cuerpo, pero que lo trasciende por ser su luz, es transcendental y por ello apertura a lo transcendental de lo real. La «cosa-real» es la cosa a la que accedemos a través de la vista, del olfato, del oído, del tacto, de la kinestesia, de la temperancia, del sentido del equilibrio, del gusto. Cada uno de estos sentidos son analizadores de una única actualidad en la que la inteligencia sentiente, la impresión intelectiva, actualiza la cosa como una esencia unitaria. Cada sentido actualiza una línea de notas o dimensión a través de sus respectos formales. El asunto es que esta pluralidad de respectos mundanales de la cosa que la actualizan como unitaria forma también parte de una única aprehensión espiritual o actualidad que, simultáneamente a la presencia de la cosa, se hace ella misma presente. Es la co-actualidad, fundamento en el pensamiento zubiriano de la presencia del espíritu a sí mismo en el mundo ${ }^{30}$. El problema reside en que, efectivamente, esta impresión originaria y sentiente de lo real y de la realidad, se ve inmediatamente modulada por la actividad «lógica» del espíritu, esto es, por la intelección dual o logos en terminología de Zubiri. El logos, sobre la base de la aisthesis, genera sentido, por lo que es muy difícil saber qué es lo que pertenece «de suyo» a la cosa real sentientemente inteligida y qué es lo que la intelección dual o de logos le añade. Evidentemente es también una cuestión que no podemos abordar aquí. Pero sí puedo, naturalmente, señalar cuál es mi posición al respecto y cómo creo que ello repercute en la estética.

En mi opinión, las diferencias entre las notas reales no son construidas por la inteligencia, sino meramente iluminadas. Ya lo he tratado en otros lugares y no

30 No es éste el lugar, naturalmente, de abordar la crítica postheideggeriana a la «metafísica de la presencia» dirigida contra toda la metafísica clásica, si ella alcanza su objetivo y si es extensible a la propuesta de Zubiri, pero tiene justamente que ver con lo que estamos tratando de si la postulación de un acceso originario a lo real a través del concepto no es en realidad una violación por parte del sujeto de los fueros y la prerrogativa propia de la realidad. 
puedo entrar aquí en detalles ${ }^{31}$. Hay, pues, un logos, naturalmente activo, pero que no construye sentido, sino únicamente co-actualiza los contenidos reales entre sí en sus mutuas diferencias. Es aquí donde se da la cosa-real que, ahora sí, en dinamismos sucesivos del logos y en unión constructa con el sentimiento, la voluntad y las sedimentaciones de lo ya vivido, van construyendo capas y capas de sentido que, ahora sí, van recubriendo la cosa-real y generando cosasentido: el mundo de humano de la vida en el que habitualmente vivimos.

La obra de arte es una cosa-sentido de enorme complejidad, pertenece, pues, al mundo de la vida. Involucra, según lo ya visto, tanto el dinamismo de la inteligencia como el de la voluntad, y particularmente del sentimiento. Aquí es también una aportación de primer orden para la estética toda la teoría zubiriana de la creación. Crear es uno de los rendimientos específicos del logos humano capaz de deconstruir libremente la complexión real de la cosa real forjando por postulación el ficto y la cosa real ficticia, ingrediente decisivo de la obra de arte, que ya Aristóteles comenzó a poner en valor, antes de que el cristianismo lo impulsara decisivamente al acentuar la condición creadora del hombre como imagen de Dios ${ }^{32}$. Esta es otra línea fundamental en la que el pensamiento de Zubiri contribuye a la estética, abriendo un campo riquísimo aún por explorar.

Pero, es necesario destacar antes de concluir este pequeño ensayo, la importancia que para la estética tiene justamente este hecho - si yo no estoy equivocado - de la condición radicalmente metafísica de la propuesta de Zubiri, en el sentido ahora indicado de una filosofía que no se reduce a hermenéutica. Gran parte de las estéticas de inspiración heideggeriana, y por lo tanto postmodernas, tienen este sesgo hermenéutico. La vida estética sólo tendría sentido dentro de la trama de sentido, valga la redundancia, de la vida intersubjetiva humana. No pretendo desde luego menospreciar esta dimensión de la vida estética: el sentido es un ingrediente fundamental de toda la vida humana en general y desde luego de la vida estética — ya he señalado que la obra de arte pertence indudablemente al mundo intersubjetivo del sentido, i.e, al mundo de la vida-, pero que se denomine precisamente estética, aisthitética, no es una casualidad, pues, justamente, la condición encarnada y sentiente de la realidad humana hace que toda nuestra vida tenga un fundamento estético, sentiente. Por ello, hay una dimensión estrictamente estética irreductible de la realidad, y también, claro está de la obra de arte en tanto que real. Esta es, en mi opinión, una de las fallas de la tradición estética platónica, que ha considerado siempre lo estético, lo sensible, como algo prescindible y a superar. No es que no crea yo que no hay «belleza invisible», es decir, belleza puramente espiritual, pero sí creo en cambio, que para nosotros los seres humanos, nuestro acceso

31 Por ejemplo, Tirado, V., «Fenomenología del logos. Zubiri y Heidegger»; en: Zubiri ante Heidegger; Nicolas, J. A. \& EspinozA, R (eds), Herder, Madrid 2008; pp. 251-284

32 Lo pone en valor Aristóteles frente a su maestro Platón al declarar la supremacía de la irrealidad de la obra poética frente al «hecho» narrado por el historiador, Cf. ARISTóteles, Poética 1451a-1451b. 
es siempre a través de la carne (al menos en este mundo, y si la Revelación cristiana es verdadera, también lo será en el otro). De aquí la importancia del soporte real de la obra de arte, ya sea en un soporte material «cósico» o ya sea el propio cuerpo humano en performances o en la danza... Pues, bien, la propuesta zubiriana evita también este deslizamiento hacia descarnalización de lo estético.

Universidad Eclesiástica San Dámaso, Madrid

Víctor Manuel Tirado San Juan

Fundación Zubiri

Universidad Pontificia de Salamanca

vtirado@sandamaso.es

[Artículo aprobado para publicación en noviembre de 2019] 